\title{
HUBUNGAN ANTARA LINGKUNGAN KERJA FISIK TERHADAP KINERJA KARYAWAN PANEN KELAPA SAWIT DI PT GUNTA SAMBA ESTATE PENGADAN
}

\section{THE RELATIONSHIP BETWEEN THE PHYSICAL LABOR ENVIRONMENT AND OF PALM OIL WORKERS IN PT GUNTA SAMBA ESTATE PENGADAN}

\author{
Dinda Chantika Maulani*1, Sri Ngapiyatun', Silvi Dwi Mentari ${ }^{1}$ \\ ${ }^{1}$ Politeknik Pertanian Negeri Samarinda, Kampus Gunung Panjang, JI. Samratulangi, Samarinda, \\ Indonesia \\ dindachantikamaulani1@gmail.com
}

\begin{abstract}
The physical occupational environment influences garden productivity and employee performance, where the better the environment, the more the productivity increases. A satisfying work environment for its employees can increase productivity and work performance. In contrast, inadequate work environments will be able to lower productivity and work performance and can eventually lower employee motivation. A working environment is said to be good or appropriate when humans can optimally carry out activities, wholesome, safe, and comfortable. The workplace harmony is seen in the long term. A poor working environment can require more labor and more time and do not support an efficient system design. The study aims to analyze the correlation between the employees' physical work environment to the performance of harvest workers in the samba estate of. Whether or not there is a correlation between the environment of employees' physical labor to the performance of employees in the samba estate of, the research is focused on the longevity of the plants, topography and safety of the harvest workers in afdeling 1 in pt gunta samba development estate. The research target is employees who work for the harvest. As for the research object is the work performance of palm harvesting employees.. It is hoped that the results will provide sufficient information to ensure that there is no link between the employees' physical work environment and the performance of employees at the age of gunta samba estate. Data collection techniques use questionnaires that have been tested as validity and religious tests. The data analysis technique used is Pearson and product product correlation analysis. Based on the results of the study using Pearson correlation and product presents the value of 0,000 which is smaller than $0.05(0,000<0.05)$, which means variable $x$ (employee physical working environment) has significant connections with variable y (employee performance).
\end{abstract}

Keywords: The Physical Environment, Employee Performance

\section{PENDAHULUAN}

Kelapa sawit merupakan salah satu tumbuhan penghasil minyak yang paling banyak diproduksi dan dikonsumsi dari seluruh dunia. Selain harganya murah, produk minyak kelapa sawit juga sangat efisien dan sangat stabil digunakan dalam berbagai produk makanan, kosmetik, dan juga digunakan sebagai sumber untuk bahan bakar atau biodiesel. Perkebunan kelapa sawit dan pengelolaan industri di Indonesia adalah kunci untuk perekonomian Negara. Pengekspor minyak sawit merupakan penghasil devisa penting dan industri yang memberikan kesempatan kerja bagi jutaan rakyat Indonesia.

Lingkungan kerja fisik mempengaruhi produktivitas dan kinerja karyawan, di mana semakin baik lingkungan maka produktivitas dan kinerja karyawan semakin meningkat. Lingkungan kerja yang memuaskan bagi karyawannya dapat meningkatkan produktivitas dan kinerja kerja. Sebaliknya lingkungan kerja yang tidak memadai akan dapat menurunkan produktivitas serta kinerja kerja dan akhirnya dapat menurunkan motivasi kerja karyawan. Suatu kondisi lingkungan kerja dikatakan baik atau sesuai apabila manusia dapat melaksanakan kegiatan secara optimal, sehat, aman, dan nyaman. Kesesuaian lingkungan kerja dapat dilihat akibatnya dalam jangka waktu yang lama. Lingkungan kerja yang kurang baik dapat menuntut tenaga kerja dan waktu yang lebih banyak dan tidak mendukung diperolehnya rancangan system kerja yang efesien.

Maka dari itu, tujuan dari penelitian ini adalah untuk: 
Penelitian ini bertujuan untuk menganalisis hubungan antara lingkungan kerja fisik karyawan terhadap kinerja karyawan panen di PT. Gunta Samba Estate Pengadan. Apakah ada atau tidak hubungan antara lingkungan kerja fisik karyawan terhadap kinerja karyawan, penelitian ini diharapkan dapat memberikan informasi yang memadai untuk memastikan adanya tidaknya hubungan antara lingkungan kerja fisik karyawan terhadap kinerja karyawan di PT. Gunta Samba Estate Pengadan.

\section{METODOLOGI}

Penelitian ini dilaksanakan di PT Gunta Samba Estate Pengadan selama 4 bulan mulai Oktober 2019 sampai januari 2020.

\section{Populasi Dan Sampel Penelitian}

Jumlah populasi dalam penelitian ini adalah seluruh karyawan panen yang bekerja di perusahaan PT. Gunta Samba Estate Pengadan yang berjumlah 186 karyawan panen. Dalam penelitian ini penulis mempersempit populasi yaitu jumlah seluruh karyawan sebanyak 186 karyawan panen dengan menghitung ukuran sampel yang dilakukan dengan menggunakan rumus slovin dengan tingkat kesalahan 10\%. Berdasarkan rumus slovin tersebut dengan tingkat kesalahan $10 \%$ maka diperoleh jumlah sampel sebanyak 65,03 sampel, namun karena subjek bilangan pecahan maka dibulatkan menjadi 65 sampel. Jadi sampel yang digunakan dalam penelitian ini sebanyak 65 karyawan panen. Sampel yang diambil berdasarkan teknik probability sampling; simple random sampling, dimana peneliti memberikan peluang yang sama bagi setiap anggota populasi (karyawan) untuk dipilih menjadi sampel yang dilakukan secara acak tanpa memperhatikan strata yang ada dalam populasi itu sendiri.

\section{Teknik Pengambilan Data}

1. Pengamatan Langsung

Mengamati lingkungan kerja fisik PT. Gunta Samba Estate Pengadan meliputi, umur tanaman kelapa sawit, topografi lahan perkebunan kelapa sawit dan keamanan kerja karyawan. Pengamatan ini dilakukan di afdelling 1 yang diamati kurang lebih 10 kali.
2. Kuesioner

Pada penelitan ini, data primer diperoleh dengan cara penyebaran kuesioner (angket). Menurut Sugiyono, Kuesioner adalah teknik pengumpulan data yang dilakukan dengan cara memberikan lembar pertanyaan atau pernyataan kepada responden untuk kemudian dijawab

3. Dokumentasi

Dokumentasi yang didapat meliputi keadaan lahan perkebunan kelapa sawit di PT. Gunta Samba Estate Pengadan.

\section{Uji Korelasi Pearson Dan Product Moment}

Untuk melihat ada tidaknya keterkaitan yang signifikan antara lingkungan kerja fisik dan kinerja karyawan, maka teknik analisa data yang digunakan adalah teknik product moment angka kasar dari Korelasi pearson.

Hasil perhitungan korelasi product moment dikonsultasikan dengan $r$ table dari taraf signifikan 5\% karena penelitian bidang sosial. Apabila $r$ hitung lebih besar dari $r$ table, maka keterkaitan antara dua variable dianggap signifikan, sebaliknya jika $r$ hitung lebih kecil dari $r$ table maka keterkaitan antara dua variable dianggap tidak signifikan.

\section{HASIL DAN PEMBAHASAN}

1. Lingkungan Kerja Fisik di PT Gunta Samba Estate Pengadan

Berdasarkan hasil penelitian pada umur tanaman kelapa sawit di PT. Gunta Samba Estate Pengadan diperoleh hasil yang dapat dilihat pada tabel 2.

Pada penelitian ini dilakukan pada tanaman kelapa sawit dengan tahun tanam 2006, memiliki tinggi batang kelapa sawit sekitar 8,9 meter yang artinya dipanen dengan menggunakan Alat Egrek yang sudah berproduksi selama 10 tahun dan tanaman kelapa sawit di PT. Gunta Samba Estate Pengadan masih masuk kedalam kategori umur ekonomis yang artinya masih berproduksi dengan baik. Umur ekonomis tanaman kelapa sawit yang dibudidayakan umumnya 25 tahun dan pohon kelapa sawit dewasa dapat tumbuh hingga 20 meter. Menurut Pahan (2008), tanaman kelapa sawit dapat dipanen pada saat tanaman berumur tiga atau empat tahun. Produksi yang dihasilkan akan terus bertambah seiring bertambahnya umur, dan akan mencapai produksi maksimalnya 
pada saat tanaman berumur $9-14$ tahun, setelah itu produksi yang dihasilkan mulai menurun

Tabel 2. Data Blok lahan Kelapa sawit PT. Gunta Samba Estate Pengadan Afdeling 1 dengan tahun tanam 2006.

\begin{tabular}{ccccc}
\hline NO & TT & $\begin{array}{c}\text { Berat } \\
\text { janjang } \\
\text { rata- } \\
\text { rata }\end{array}$ & $\begin{array}{c}\text { Luas } \\
\text { Tanam } \\
\text { (ha) }\end{array}$ & $\begin{array}{c}\text { Jumlah } \\
\text { Pokok } \\
\text { TM }\end{array}$ \\
\hline 1 & 2006 & 20.87 & 29.98 & 3,967 \\
2 & 2006 & 21.06 & 27.26 & 3,614 \\
3 & 2006 & 20.71 & 30.83 & 4,153 \\
4 & 2006 & 21.03 & 29.31 & 3,997 \\
5 & 2006 & 20.68 & 25.98 & 3,531 \\
6 & 2006 & 20.96 & 32.89 & 4,488 \\
7 & 2006 & 22.27 & 28.23 & 3,844 \\
8 & 2006 & 20.29 & 30.51 & 4,043 \\
9 & 2006 & 19.24 & 27.79 & 3,701 \\
10 & 2006 & 21.67 & 28.44 & 3,855 \\
11 & 2006 & 19.52 & 27.8 & 3,762 \\
12 & 2006 & 20.25 & 29.87 & 4,041 \\
13 & 2006 & 21.1 & 26.5 & 3,579 \\
14 & 2006 & 20.97 & 28.12 & 3,761 \\
15 & 2006 & 23.02 & 26.69 & 3,625 \\
16 & 2006 & 21.21 & 28.24 & 3,841 \\
17 & 2006 & 21.55 & 28.32 & 3,826 \\
\hline
\end{tabular}

Tabel 3. Topografi lahan perkebunan kelapa sawit di PT. Gunta Samba Estate Pengadan

\begin{tabular}{cccc}
\hline No & No Blok & Keterangan & $\begin{array}{c}\text { Basis } \\
\text { JJG }\end{array}$ \\
\hline 1 & G17P06 & Berbukit & 45 \\
2 & G18P06 & Berbukit & 45 \\
3 & G19P06 & Berbukit & 45 \\
4 & G20P06 & Berbukit & 45 \\
5 & G21P06 & Berbukit & 45 \\
6 & G22P06 & Berbukit & 45 \\
7 & G23P06 & Berbukit & 45 \\
8 & G24P06 & Berbukit & 45 \\
9 & H16P06 & Berbukit & 45 \\
10 & H17P06 & Berbukit & 45 \\
11 & H18P06 & Berbukit & 45 \\
12 & H19P06 & Berbukit & 45 \\
13 & H20P06 & Berbukit & 45 \\
14 & H21P06 & Berbukit & 45 \\
15 & H22P06 & Berbukit & 45 \\
16 & H23P06 & Datar & 55 \\
17 & H24P06 & Berbukit & 45 \\
\hline
\end{tabular}

Berdasarkan hasil penelitian pada topografi lahan perkebunan kelapa sawit di PT. Gunta Samba Estate Pengadan diperoleh hasil yang dapat dilihat pada tabel 3 .

Kondisi topografi pertanaman kelapa sawit sebaiknya tidak lebih dari kelerengan $30 \%$ agar pertumbuhan dan produksinya maksimal dan biaya yang dibutuhkan sangat tinggi. Penelitian ini dilakukan di afdeling 1 yang memiliki topografi berbukit dengan kelerengan $15 \%$ - 30\%. Pada Lahan topografi berbukit memiliki standar basis janjang yaitu 45 dan pada lahan datar memiliki standar basis janjang yaitu 55. Menurut Djafar dan Purba (2001), Topografi lahan pada perkebunan kelap sawit sangat berpengaruh terhadap produksi dan kapasitas pemanen. Daerah yang bertopografi datar akan mempermudah dalam proses pemanenan TBS dan pengangkutan buah di banding di lahan miring/berbukit. Pada daerah bergelombang/berbukit pemanen mengalami kesulitan dalam melaksanakan panen karena perindahan dari satu pohon ke pohon yang lain harus lebih berhati-hati. Ooleh karena itu areal yang kemiringan dengan lerengnya $>15 \%$ perlu dilakukan upaya konservasi lahan miring seperti pembuatan tapak kuda, teras kontur tangga-tangga panen.

Berdasarkan observasi atau pengamatan di lapangan pada karyawan panen di PT. Gunta Samba Estate Pengadan, diketahui bahwa PT. Gunta Samba Estate Pengadan memberikan fasilitas Alat Pelindung Diri (APD) untuk keamanan karyawan panen saat proses pemanenan kelapa sawit dan perusahaan pun memberikan pengawasan terkait penggunaan APD saat bekerja. Sistem pengawasan di lapangan hanya sebatas memberikan teguran dan mengingatkan secara lisan agar karyawan tetap menggunakan alat pelindung diri, hanya saja masih banyak karyawan yang tidak menggunakannya pada saat bekerja.

Untuk mengetahui bagaimana kondisi keamanan lingkungan kerja fisik di PT. Gunta Samba Estate Pengadan, peneliti membagi menjadi tiga kategori yaitu, Sangat baik, cukup baik, dan tidak baik. Azwar (2012) mengemukakan bahwa "tujuan kategorisasi adalah untuk menempatkan individu ke dalam kelompok terpisah secara berjenjang menurut suatu kontinum berdasar atribut yang diukur". Dan untuk menentukan jarak pada masingmasing tingkat klasifikasi terlebih dahulu harus mencari rata-rata skor total (mean) dan standar 
deviasi serta skor tertinggi dan terendah dari kuesioner dengan indikator keamanan yang diolah dengan menggunakan SPSS 20, disajikan pada Tabel 4.

$$
\text { Penilaian karyawan terhadap }
$$

keamanan pada lingkungan kerja fisik adalah dari 65 responden sebagai subjek penelitian diperoleh 14 responden (22\%) menyatakan bahwa keamanan lingkungan kerja fisik sangat baik, 39 responden $(60 \%)$ menyatakan baik, dan 12 responden (18\%) menyatakan tidak baik. Maka dapat disimpulkan bahwa keamanan lingkungan kerja fisik di PT. Gunta Samba Estate Pengadan masuk dalam kategori penilaian baik.

Tabel 4. Penilaian responden terhadap keamanan lingkungan kerja fisik di PT. Gunta Samba Estate Pengadan

\begin{tabular}{|c|c|c|c|}
\hline Klasifikasi & Skor & Frekuensi & $\begin{array}{c}\text { Presentase } \\
(\%)\end{array}$ \\
\hline $\begin{array}{l}\text { Sangat } \\
\text { Baik }\end{array}$ & $>23,5$ & 14 & 21.5 \\
\hline Baik & $23-23,5$ & 13 & 20.0 \\
\hline $\begin{array}{l}\text { Cukup } \\
\text { Baik }\end{array}$ & $22-22,5$ & 14 & 21.5 \\
\hline Tidak Baik & $21-21,5$ & 12 & 18.5 \\
\hline $\begin{array}{l}\text { Sangat } \\
\text { Tidak Baik }\end{array}$ & $<20,5$ & 12 & 18.5 \\
\hline Total & 65 & 100.0 & \\
\hline
\end{tabular}

Keamanan adanya jaminan keamanan terhadap milik pribadi dan dirinya sendiri akan membuat karyawan merasa tenang dalam bekerja. Berdasarkan penelitian, keamanan karyawan ditanggung oleh PT. Gunta Samba Estate pengadan. Perusahaan memberikan fasilitas Alat Pelindung Diri (APD), memberikan penggantian biaya pengobatan, pemeriksaan kesehatan dan perawatan di rumah sakit dan dokter mana saja dengan syarat adanya surat keterangan bahwa karyawan yang bersangkutan diharuskan untuk dirawat dirumah sakit yang lebih besar dan lengkap.

2. Kinerja Karyawan Panen di PT Gunta Samba Estate Pengadan

Penelitian ini dilakukan dengan mengamati 15 karyawan panen yang melakukan pemanenan di blok G20 dan blok G21 sebagai perwakilan dari 65 responden. Berdasarkan hasil tabel Dari 15 karyawan panen melakukan pemanenan dengan hasil yang lebih dari pada standar basis yang ditentukan oleh PT. Gunta samba Estate
Pengadan yang dilakukan didua blok yaitu blok G20 dan G21.

Tabel 5. Penilaian responden terhadap Kinerja Karyawan panen di PT. Gunta Samba Estate Pengadan.

\begin{tabular}{|c|c|c|c|}
\hline Klasifikasi & Skor & Frekuensi & $\begin{array}{c}\text { Presentase } \\
(\%)\end{array}$ \\
\hline Sangat Baik & $\begin{array}{c}\text { lebih } \\
\text { dari } 70\end{array}$ & 5 & 8 \\
\hline Baik & $64-70$ & 51 & 78 \\
\hline Tidak Baik & $\begin{array}{l}\text { Kurang } \\
\text { dari } 64\end{array}$ & 9 & 14 \\
\hline Tota & & 65 & 100 \\
\hline
\end{tabular}

Kinerja karyawan sangat berpengaruh besar terhadap kinerja perusahaan, apabila kinerja karyawan dalam suatu perusahaan rendah maka bisa dipastikan kinerja perusahaan tersebut akan rendah juga. Oleh karena itu, faktor-faktor yang mempengaruhi kinerja harus diperhatikan karena akan berdampak langsung terhadap karyawan itu sendiri. Faktor-faktor yang mempengaruhi kinerja seorang karyawan terbagi menjadi dua, yaitu faktor internal dan eksternal. Faktor internal meliputi minat, bakat, pengetahuan, etos kerja, motivasi kerja, dan lain-lain. Sedangkan faktor eksternal meliputi peraturan perusahaan, suasana kerja, kondisi ekonomi, sarana prasarana, dan lain-lain.

Kinerja seorang karyawan sendiri dapat dilihat dari berbagai aspek, yaitu kuantitas dari hasil pekerjaannya, kualitas dari hasil pekerjaannya, ketepatan waktu dari hasil pekerjaannya, kehadiran pada saat jam kerja.

3. Hubungan Antara Lingkungan Kerja Fisik terhadap Kinerja Karyawan Panen di PT Gunta Samba Estate Pengadan

Berdasarkan hasil penelitian yang telah dilakukan menunjukan bahwa hubungan positif dan signifikan antara lingkungan kerja fisik karyawan terhadap kinerja karyawan panen di PT. Gunta Samba Estate Pengadan. Pernyataan ini dibuktikan dengan hasil perhitungan Pearson Correlation yang menghasilkan

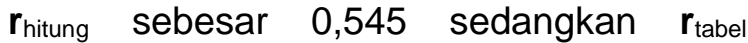
dengan taraf signifikan $5 \%$ yaitu 0,244 maka $\mathbf{r}_{\text {hitung }}>\mathbf{r}_{\text {tabel }}(0,545>0,244)$, perbandingan tersebut mengartikan bahwa Ho ditolak dan Ha diterima yaitu terdapat hubungan yang positif dan signifikan antara 
lingkungan kerja fisik karyawan terhadap kinerja karyawan di PT. Gunta Samba Estate Pengadan.

Tabel 6. Uji Korelasi dan Product Moment Lingkungan Kerja Fisik dan Kinerja

\begin{tabular}{lll}
\hline \multicolumn{1}{c}{$\mathrm{X}$} & $\mathrm{Y}$ \\
\hline Pearson Correlation & 1 & $.545^{* *}$ \\
Sig. (2-tailed) & & 000 \\
$\mathrm{~N}$ & 65 & 65 \\
Pearson Correlation & $.545^{* *}$ & 1 \\
Sig. (2-tailed) & .000 & \\
N & 65 & 65 \\
\hline
\end{tabular}

Hubungan antara lingkungan kerja fisik dengan kinerja karyawan memiliki artian bahwa karyawan akan merasa nyaman dengan kondisi lingkungan kerja yang ada jika kondisi lingkungan tersebut sesuai dengan dirinya dan tidak merasa terganggu ketika mereka bekerja, sehingga dengan kenyamanan tersebut mereka terpacu dalam bekerja, hal ini menyebabkan banyak pekerjaan yang dapat terselesaikan dengan baik sehingga kinerja mereka pun dapat dikatakan baik. Hubungan manusia dengan mesin serta peralatan-peralatannya dan lingkungan kerja dapat dilihat sebagai hubungan yang unik karena interaksi hal-hal tersebut dapat membentuk suatu sistem kerja yang tidak sederhana. Pengertian kinerja sendiri yaitu hasil kerja dari seorang karyawan selama dia bekerja dalam menjalankan tugas-tugas pokok jabatannya yang dapat dijadikan sebagai landasan apakah karyawan itu bisa dikatakan mempunyai prestasi kerja yang baik atau sebaliknya.

\section{KESIMPULAN}

Berdasarkan hasil uji hipotesis yang diperoleh dengan menggunakan uji korelasi pearson dan product moment yang diolah dengan menggunakan SPSS 20, maka dapat disimpulkan bahwasanya terdapat hubungan yang cukup kuat dan signifikan antara lingkungan kerja fisik karyawan terhadap kinerja karyawan panen kelapa sawit di PT. Gunta Samba Estate Pengadan.
Adapun taraf signifikansi $(p)$ sebesar 0,000 taraf signifikansi tersebut lebih kecil daripada taraf signifikansi $0,05 \quad(p<0,05)$, ini berarti korelasi tersebut signifikan. Hal ini menandakan bahwa $\mathrm{Ho}$ ditolak dan $\mathrm{Ha}$ diterima yang menyatakan bahwa ada hubungan antara antara lingkungan kerja fisik karyawan terhadap kinerja karyawan panen kelapa sawit di PT. Gunta Samba Estate Pengadan. Berdasarkan koefisien korelasi sebesar 0,545 dimana hasil penelitian menunjukan adanya hubungan positif yang cukup kuat antara lingkungan kerja fisik karyawan terhadap kinerja karyawan panen kelapa sawit di PT. Gunta Samba Estate Pengadan di perusahaan tersebut.

\section{DAFTAR PUSTAKA}

Afani, M Z. 2008. Hubungan presepsi lingkungan kerja dengan kepuasan kerja karyawan di perusahaan daerah air minum (PDAM) kota madiun. Universitas Islam Negeri (UIN) Malang.

Azwar, S. 2012. Penyusunan Skala Psikologi. Yogyakarta: Pustaka Pelajar.

Bahri, M S. 2018. Pengaruh kepemimpinan lingkungan kerja, budaya organisasi dan motivasi terhadap kepuasan kerja yang berimplikasi terhadap kinerja dosen. Surabaya: Jakad Publishing

Cooper, Cary dan Straw, Alison. 1995. Setres Managemen yang sukses. Jakarta: Kesain blanc

Eko, W S. 2015. Manajemen Pengembangan Sumber Daya Manusia. Yogyakarta: Pustaka Pelajar

Fidianto, Afid. 2012. Hubungan antara lingkungan kerja dengan kinerja karyawan di PT. Pertamina (Persero) Surabaya. Institut Agama Islam Negeri Sunan Ampel.

Foster, B dan Karen, R. 2001. Pembinaan untuk meningkatkan kinerja karyawan. Jakarta: PT. Toko Gunung Agung

Gibson J L. Dkk. 1997. Organisasi dan Manajemen. Jakarta: Erlangga

Ginanjar, R A. 2013. Pengaruh lingkungan kerja terhadap kinerja karyawan pada dinas pendidikan, pemuda, dan olahraga kabupaten sleman. Universitas Negeri Yogyakarta.

Kasmawati. 2014. Pengaruh Lingkungan kerja terhadap kinerja karyawan pada PT. 
Sermani Steel Makasar. Universitas Islam Negeri Alauddin Makassar.

Kusriyanto, B. 1991. Meningkatkan produktivitas karyawan. Jakarta: PT. Pustaka

Mangkunegara, P M. 2007. Manajemen sumber daya manusia perusahaan. Bandung: PT Remaja Rosdakarya.

Murty, W A dan Hudiwinarsih, G. 2012. Pengaruh kompensasi, motivasi dan komitmen organisasional terhadap kinerja karyawan bagian akuntansi. Surabaya: STIE Perbanas

Mathis, L R dan John, J. 2006. Human Resource Managemen. Jakarta: Salemba empat

Nawawi, Hadari. 2010. Perencanaan sumber daya manusia untuk organisasi. Profit yang kompetitif. Yogyakarta. UGM Press.men

Ridwan \& Sunarto. 2010. Pengantar statistika untuk penelitian: pendidikan sosial, komunikasi, ekonomi bisnis. Bandung: Alfabeta.

Robbins, S dan Coulter, M. 2002. Manajemen. Jakarta: Gramedia

Sayidah, N. 2018. Metode penelitian disertai dengan contoh penerapannya dalam penelitian. Sidoarjo: Zifatama Jawara.

Siagian, S P. 2001. Manajemen sumber daya manusia. Jakarta: Bumi Aksara

Sugiyono. 2007. Metode penelitian kuantitatif kualitatif dan R\&D. Bandung: Alfabeta.

Sugiyono. 2010. Metode penelitian pendidikan kuantitatif, kualitatif dan R\&D. Bandung: Alfabeta.

Sugiyono. 2010. Statistika untuk penelitian. Bandung: Alfabeta

Sugiyono. 2011. Metode penelitian Kuantitatif, kualitatif dan R\&D. Bandung: Alfabeta

Sujianto, A E. 2009. Aplikasi statistic dengan SPSS 16.0. Jakarta: Prestasi Pustakarya

Sukmanala, S. 2007. Manajemen Kinerja, langkah-langkah efektif untuk membangun, mengendalikan dan evaluasi kinerja. Jakarta: PT. Intermedia Utama.

Umar, H. 2000. Research methods in finance and banking. Jakarta: PT Gramedia Pustaka Utama. 